\title{
Perspective
}

\section{The Need for Balanced Health Policies to Avoid Path Dependent Medicine}

\author{
Amirhossein Takian $^{1,2, *}$ \\ ${ }^{1}$ Division of Health Studies, School of Health Sciences \& Social Care, Brunel University, London, Uxbridge, UK \\ ${ }^{2}$ National Academy of Medical Sciences, Tehran, Iran
}

Received: 1 June 2013, Accepted: 12 June 2013, ePublished: 12 June 2013

\section{KEY QUESTIONS}

- Looking at the past, do you think that health policy arena has been successful to make healthy policies for all human kind? - Has the time arrived to move from evidence-based policy making towards need-based, futuristic, and healthy health policy making?

- If so, how can we make this shift happening?

\section{Background}

Health policy has been intrinsically linked to economic, financial, social, and regional policy. Global efforts and governmental commitments to making healthy public policies and improving health conditions have been phenomenally extensive and comprehensive in the course of the last few decades. The millennium development goals (MDGs) and valuable attempts by international and supranational bodies, i.e. World Health Organization (WHO); World Bank; Global Fund to fight Tuberculosis (TB), Malaria and AIDS; Gates Foundation, to count a few, have been fundamentally exemplar in improving global health, particularly for the poor. After the second world war, particularly in the period of the last 20 years, technological advances have brought magical outcomes to human life. For example, HIV/AIDS was terrifying 10 years ago. Although it is still an international concern and frightening for many nations, recent advances to cure and manage HIV positive patients have been astounding. There are types of cancers that are considered curable today, most of which would have killed people even at the beginning of the millennium. Unfortunately, millions of people still die from conditions such as malaria and TB. However, the progress made in their management was unthinkable 20 years ago. Similarly, advances in stem cell research have shed light on some very challenging fields of medicine and public health, most of which were inconceivable a short time ago. Thousands of others may be added to the list.

\section{The role of health technologies and technologies for health in achieving advances}

As identified in the 1999 World Health Report, "half the gains in health between 1952 and 1992 result from access to better technology" (taking a very broad view of technology; every advance not related to income or education). Antimicrobial drugs are one of the most used types in the list of medical technologies. Over the $20^{\text {th }}$ century, contemporary healthcare was established on the ashes of the dark past, being somewhat assured that bacterial infections are preventable or can be treated by antibiotics. Such belief was strong to the extent that the United States Surgeon General famously proclaimed in 1968 that "the war against diseases has been won" (1). In the course of the last 50 years, the predominant assumption was that in case of bacterial resistance to some antimicrobials, there will always be others to be used (2). Successful tackling of many infectious diseases through integration of antibiotics in almost all aspects of healthcare, has been the cornerstone of many advances in modern, heavily technology-based, and invasive medicine and public health. This has led us to successfully manage more chronic conditions and live longer than ever. Smith and Coast count few among many: antimicrobials as standard to prevent iatrogenic infection in surgical care (3), to women delivering by caesarean section (4), and to those having cancer treatment (5).

\section{The two strong challenges}

The above-mentioned advances warrant big applause and celebration across the globe. However, two powerful threats are about to destroy all achievements and divert us back to the dark ages of pre-antibiotic era, and an apocalyptic scenario may be looming (2). First, antibiotics may no longer safeguard healthcare advances (6) due to a rapid decline in the number of new drugs approved, massive bacterial resistance to existing antibiotics, and the painful consensus that "the existing classes of antibiotics are probably the

*Corresponding author: Amirhossein Takian; Email: amir.takian@brunel.ac.uk 
best we will ever have" (7). Second, unequal development, distribution, and utilisation of health technologies and technologies for health among various nations have deeply widened the gap between the rich and poor, endangering the effectiveness of such advances.

\section{Why is this the case?}

The main reason, I argue, is our imbalanced and unhealthy health policy making. For a considerable time period, we have victimized societal and global need-based and futuristic health policy making to evidence-based policy making, which prioritizes health problems by economic burden and cost effectiveness of interventions (8), and distorts need-based measures as not cost-effectively enough to become a health priority. Unfortunately, the cost of overlooking basic but fundamental health issues and needs of all people, wherever they are around the globe, when prioritizing the policies has been massive. Should we continue such negligence and not review the trajectory of our unhealthy health policy making, we may inevitably be diverted to the dark ages of the past, when millions died within a short time period. The disastrous consequences of our unbalanced and unhealthy health policies will be for all nations, including high, middle, and low income countries. This resembles what the American writer and futurist, Alvin Toffler, describes in the book entitled: "The Third Wave", 1980; that we may return to the agricultural era, after we have experienced a Utopian technology savvy time, like the current 'information society'. Let me assure you that this claim is not exaggerated and we urgently need to make health policies differently, namely balanced, need-based, and community oriented.

As for antimicrobials, our enthusiasm to invest in technology-savvy medicine has led us to underestimate the power of pathogens and made us reluctant to tackle them, resulting them to become stronger and stronger. On one hand, we have not made more than few antibiotics in the course of the past two decades. Worse still, we have overprescribed/used the existing antibiotics, jeopardizing the effectiveness of the majority of the current antimicrobials. The result of this unfortunate combination is horrifying. Smith and Coast project that the costs of resistance are not limited to those associated with additional treatment for a primary infection, but encompass the costs that might relate to the loss of modern healthcare, briefly described above (2). They argue that in the same way that health systems need adequate and functional health workers to be effective, they also require effective antimicrobials to perform and maintain. In other words, bacterial resistance to current antibiotics is not just an infectious disease issue; it is a surgical issue, a cancer issue, an entire global health system issue. This is so serious that they suggest that in the future we may be required to rethink developing our health system, i.e. redesigning many facilities or reintroducing sanatoriums if effective antibiotic treatments are no longer available.

Lack of attention to the development of antibiotics in the course of the past 20 years is partly relevant to inequality in prioritising health issues, leading to imbalanced policy making for health. Unequal development, distribution and utilisation of technologies for health and health technologies, plus skewed access to advances in managing health services towards wealthy nations, have distorted the picture of global health quite meaningfully. Most health technologies are produced by companies from high-income countries (HICs) for HIC markets. The top 30 companies accounting for $89 \%$ of health technologies revenues, all have their head quarters in HICs, 19 in the United States of America, with $87 \%$ of their sales in European Union countries (plus Norway), Japan, and USA (9).

Furthermore, most health technologies have been designed for an environment with high spending on health, a reliable energy supply, and large numbers of trained health-care professionals. These conditions are dreamlike for the 2.47 billion people (almost one third of world population), most of whom live in low and middle income countries, and on the equivalent of less than US\$2 a day. They have little money, underdeveloped infrastructure, and few health-care workers for such advances (10). Simultaneously, within countries, i.e. rich nations, it is fair to say that many health policies have failed, where the gap between rich and poor has been growing ever wider and where there seems to be a steadily eroding commitment to an inclusive social contract. Cited by Heath, the Norwegian writer Gunnar Kopperud, in his 1998 novel 'The Time of Light' notes that "a railway station mirrors the soul of the place where it's located." Heath concludes "perhaps in the same way a health service reflects the soul of the society it serves" (11). Would it be right therefore to assume that the international health policy making arena has lost its balance when the 10/90 gap has stayed unchanged for some time: $10 \%$ of the global budget for health is spent on low-income countries, accounting for $90 \%$ of the global burden of diseases? Worse still, in the period of 1975-1997, out of 1223 drugs reaching the global market, 13 (1\%) were produced for combating tropical diseases, counting for many health burdens in developing countries (12)!

Reflecting on the past, we seem to have been obsessed with investing in fashionable and exciting areas such as molecular medicine, cancer, stem cell research, and so on, at the expense of ignoring the more palpable priorities of global health. Moreover, we have over-emphasized evidence-based policy making, which is mostly based on randomized control trials and heavily positivist views of the world $(13,14)$ at the price of misallocation of many resources and abandoning many priorities. As a result, we may know how to produce a heart in the lab, but we are clueless in treating an antibiotic resistant pneumonia and may simply die from it. Such path dependent Dickensian medicine' derives partly from losing the balance in prioritizing issues and making appropriate policies to address them.

Imbalances in humans' policy making and the following negative and somewhat disastrous consequences are not limited only to health. Global warming is another typical example. Thanks to advances in the aviation industry, we are able to travel by airplane from everywhere to almost everywhere, including eminently the moon, at a very affordable price. However, the overuse of airspace and our massive production of carbon footprint have destroyed our planet and our environment to the extent that there may be no livable place to enjoy our cheerful advances in near future! 
How to foster balanced and healthy policy making at a time that scientific and technological advances continue to increase costs, while the global financial crisis is placing huge pressure on governments to control cost, limit demand, and reduce spending (15)? This dilemma is hard to resolve, particularly at the time of economic austerity and liaising with policy makers, member of advisory groups, scientists, and other stakeholders, many of them have been traditionally concerned with biomedicine, pharmaceuticals, and medical technologies to drive the process for setting priorities and making major health policies $(16,17)$. Worse still, and as a result of above, a very tiny proportion of health budget has been allocated to innovating trajectories of making healthy policy. As an indicator, only $4 \%$ of the $€ 642$ million cooperation programme of the European Commission's for health research in 2011 was allocated to health systems, public health, or health policy research (18). To see the magnitude of how far it is to deliver the expectations, $25 \%$ of such budget was speculated for such purposes.

\section{Conclusion}

The crucial need to make balanced health policies is clear. We have to learn from history to make better policies (19). In particular, three questions are essential to be discussed:

1- Why have we lost the steer of health policy making against need-based and balanced policies for health?

2- How to bridge such a gap and make more sensible policies for all (as against elite)?

3- What methodological aspects should be considered to improve the process of healthy policy making?

We would welcome your contributions in answering these questions. The IJHPM invites the readers; i.e. scientists, policy makers, advocacy groups, health professionals, and all interested people, from around the globe, to contribute to this inquiry and shed light on practical ways of making balanced health policies, to fence guard the cornerstone of healthy health policy, and to ultimately prevent a disaster from happening.

\section{Acknowledgements}

The views expressed here are solely those of the author and not necessarily the author's affiliation. I am grateful to Dr. Ali-Akbar Haghdoost and Dr. Arash Rashidian for their valuable comments on the first drafts of this manuscript.
3. Cars O, Hogberg LD, Murray M, Jasper W, Nordberg O, Sivaraman S, et al. Meeting the challenge of antibiotic resistance. BMJ 2008; 337:7268.

4. Bratzer DW, Houck PM. Antimicrobial prophylaxis for surgery: an advisory statement from the National Surgical Infection Prevention Project. Clin Infect Dis 2004; 38: 1706-15.

5. Wild SM. Antibiotic prophylaxis at caesarean section. Lancet 2002; 360: 724.

6. So AD, Ruiz-Esparza Q, Gupta N, Cars O. 3Rs for innovating novel antibiotics: sharing resources, risks, and rewards. BMJ 2012: 344: e1782.

7. Cormican M, Vellinga A. Existing classes of antibiotics are probably the best we will ever have. BMJ 2012; 344: e3369.

8. Coast J, Smith RD, Millar MR. Disentangling value: assessing the benefits of containing antimicrobial resistance. In: Roberts J, ed. The economics of infectious disease. Oxford University Press; 2006: 201-14. 9. Walshea K, McKeeb M, McCarthyc M, Groenewegend P, Hansene J, Figueras $\mathrm{J}$, et al. Health systems and policy research in Europe: Horizon 2020. Lancet 2013 Mar 15. [In press]

10. World Bank, World Bank annual report, 2012.

11. Heath I. Words are all we have. BMJ 2011; 343: d7166.

12. Global Forum for Health Research .Monitoring financial flows for health research. Geneva: Global Forum for Health Research. 2004. (cited 2013 May 17) Available at: http://www.globalforumhealth.org 13. Takian A, Petrakaki D, Cornford T, Sheikh A, Barber N. Building a house on shifting sand: Methodological considerations when evaluating the implementation and adoption of national electronic health record systems. BMC Health Serv Res 2012, 12:105.

14. Greenhalgh T, Russell J. Why do evaluation of ehealth programs fail? An alternative set of guiding principles. PLoS Med 2010; 7: e1000360.

15. European Commission, COM 211(811). Proposal for a council decision establishing the specific programme implementing horizon 2020 - the framework programme for research and innovation (20142020). Brussels: European Commission, 2012.

16. Howitt P, Darzi A, Yang G-Z, Ashrafian H, Atun R, Barlow J, et al. Technologies for global health. Lancet 2012; 380: 507-35.

17. HSR Europe. Health services research into European policy and practice. Utrecht: Netherlands Institute for Health Services Research; 2011.

18. McCarthy M. Public health research-Europe's future (STEPS report). London: University College London, 2011. (accessed 2013 May 21). Available at: http://discovery.ucl.ac.uk/1329165

19. Takian A, Cornford T. NHS information: Revolution or evolution? Health Policy and Technology 2012, 1:193-198.

Ethical issues

Not applicable.

Competing interests

None.

Author's contribution

AT is the single author of the manuscript.

\section{References}

1. Gregor M. Bird flu: a virus of our own hatching. Lantern Books; New York: 2006.

2. Smith R, Coast J. The true cost of antimicrobial resistance. BMJ 2013; 346: f1493. 